\title{
Lithium in drinking water and suicide rates across the East of England ${ }^{\dagger}$
}

Nikolett Kabacs, Anjum Memon, Thom Obinwa, Jan Stochl and Jesus Perez

\section{Summary}

Lithium can be found naturally in drinking water. In clinical practice, it is widely used in pharmacological doses for the treatment of bipolar disorder; and may also prevent suicida behaviour in people with mood disorders. In two studies, lithium levels in tap water have been significantly and negatively correlated with suicide. We measured lithium levels in tap water in the 47 subdivisions of the East of
England and correlated these with the respective suicide standardised mortality ratio in each subdivision. We found no association between lithium in drinking water and suicide rates across the East of England from 2006 to 2008

\section{Declaration of interest}

None.
Lithium is found naturally in variable amounts in food and water; and is widely and effectively used in pharmacological doses in psychiatry for the treatment and prevention of manic and depressive episodes. Mood disorders are characterised by a 30-50 times increased risk of suicide that can be reduced with lithium treatment. ${ }^{1,2}$ Lithium has also been found to have an anti-suicidal property that might be independent from its moodstabilising effect. ${ }^{3}$ The recommended serum levels for lithium range between 0.6 and $1.0 \mathrm{mmol} / \mathrm{l}$ for maintenance therapy of bipolar disorder. ${ }^{4}$ However, the optimal blood level at which lithium exerts a possible preventive effect against suicide has not been confirmed. In an ecological study in 1990, Schrauzer \& Shrestha reported that the average suicide rates in 27 counties of Texas, USA, over a 10-year period, were consistently lower in counties with relatively high natural lithium content in the drinking water compared with those with medium or low content. ${ }^{5}$ Recently, Ohgami et al examined lithium levels in tap water in the 18 municipalities of Oita prefecture in Japan, and correlated these with the standardised mortality ratios (SMRs) for suicide in each municipality. They found that lithium levels in tap water were significantly and negatively correlated with SMRs across that particular region in Japan. Based on this correlation, the authors hypothesised that lithium in drinking water may be associated with the risk of suicide in the general population. ${ }^{6}$ Since the publication of this report in 2009, there has been considerable debate in the scientific literature and print/electronic media regarding the possibility of adding lithium to drinking water supplies to benefit community mental health. The study, however, has been criticised for not accounting for potential confounding factors, ecological fallacy, methodology and interpretation of the findings. ${ }^{7-11}$ To further test this hypothesis, we conducted an ecological study in the East of England to examine whether there was an association between naturally occurring lithium levels in drinking water and mortality from suicide.

\section{Method}

The East of England is one of the nine official regions of England, UK, and it is made up of six counties (Essex, Hertfordshire,

'See pp. 336-337, this issue
Bedfordshire, Cambridgeshire, Norfolk and Suffolk), which are further divided into 47 subdivisions. In 2007, the population in each of the subdivisions in the East of England varied from 62200 to 188800 , with a total population of 5.7 million (www. statistics.gov.uk).

We obtained indirectly SMRs of suicide (ICD- $10^{12}$ codes: X60-X84) for the period 2006-2008, for the 47 subdivisions of the East of England as reported in the NHS Clinical and Health Outcome Knowledge Base (www.nchod.nhs.uk).

We obtained drinking (tap) water samples from publicly accessible sources (restaurants, public toilets, pubs, cafeterias and petrol stations) in the 47 subdivisions. The samples were collected in $120 \mathrm{ml}$ sterilised plastic containers provided by Eurofins UK (www.eurofins.co.uk). We obtained one water sample of $100 \mathrm{ml}$ from each subdivision in the East of England. Sample containers were submitted for analysis within $48 \mathrm{~h}$ of collection. No specific storage requirements were advised by the laboratory. Lithium levels were measured by Eurofins UK, using inductively coupled plasma mass spectrometry. Collection of all water samples and analysis of lithium levels were performed in the calendar year 2010.

We used Pearson's correlation coefficient $(r)$ and bivariate scatter plots to investigate the association between lithium levels in drinking water and suicide SMRs in the 47 subdivisions of the East of England.

\section{Results}

Overall, for the 3-year period 2006-2008 (pooled), the SMR for suicide in the East of England was 98, varying from 36 to 194 across all the subdivisions. The SMR in males was 95 (range 35-213) and in females 108 (range 0-292).

Lithium levels in drinking water ranged from $<1$ to $21 \mu \mathrm{g} / \mathrm{l}$ across the 47 subdivisions of the East of England. The distribution of these levels in this large geographical area revealed little or no variation if the water was supplied by the same company.

The analyses of these data showed that there was no correlation between lithium levels in drinking water and the suicide SMRs in the 47 subdivisions of the East of England ( $r=-0.054, P=0.715$ for males; $r=0.042, P=0.777$ for females; $r=-0.03, P=0.838$ for both genders). Similarly, the bivariate scatter plots showed no association between lithium levels in drinking water and the suicide SMRs (Fig. 1). 


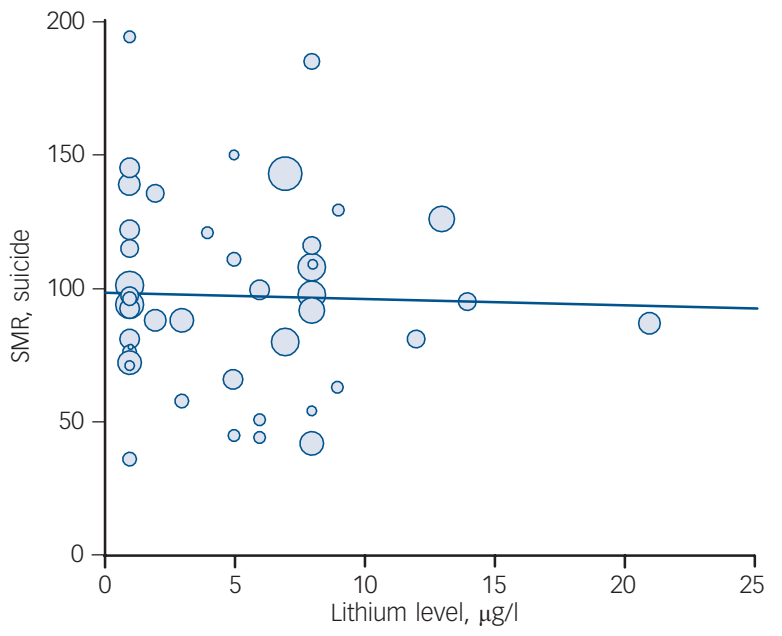

Fig. 1 Lithium levels in drinking (tap) water and standardised mortality ratios (SMRs) for suicide from 2006 to 2008 (pooled) in the 47 subdivisions of the East of England. The size of the dot represents population size in each subdivision.

\section{Discussion}

Contrary to the two previous studies (from USA in 1990 and Japan in 2009), we found no association between lithium levels in drinking (tap) water and mortality from suicide in the East of England, a region with a total population of 5.7 million. A variety of factors may have played a part in these differing results. For example, Ohgami et al weighted data by population sizes within the 18 municipalities of the Oita prefecture (population 1.2 million). ${ }^{6}$ It raises the possibility that the apparent negative correlation was perhaps as a result of a single measurement point, i.e. Oita city had the largest population $(n=463973,38 \%)$. In the East of England, there was relatively little variation in population size across the 47 subdivisions. Also, the lithium levels in drinking water in Texas and in the Oita prefecture ranged from 0 to $160 \mu \mathrm{g} / \mathrm{l}$, and 0.7 to $59 \mu \mathrm{g} / \mathrm{l}$, respectively. ${ }^{5,6}$ These values represent a much wider range and higher top level than those found in the East of England $(<1-21 \mu \mathrm{g} / \mathrm{l})$. Accordingly, the normal distribution of serum levels of lithium in these populations might also differ, and be hypothetically responsible for the discrepancy between these results and the respective suicide rates.

All these populations could also differ with regard to ethnic, religious and social class distribution, prevalence and management of mental disorders and mobility patterns. In 2008, the East of England had one of the highest total net in-migration rates of all English regions, of which half was due to international in-migration (www.statistics.gov.uk). However, mobility patterns are unlikely to influence the regional suicide rates in the East of England, as an incident of suicide is only assigned to a particular subdivision if the individual has been resident in that subdivision for at least 6 months.

It is still not clear what amount of lithium in human serum can provide an independent protective effect for suicide. The naturally occurring serum levels of lithium in adults range between 7 and $28 \mu \mathrm{g} / \mathrm{l}(0.001-0.004 \mathrm{mmol} / \mathrm{l}) ;^{13}$ nonetheless, the supposedly preventive therapeutic level to prevent suicide has only been tested with serum levels that are considered effective for prevention of relapse in mood disorders $(0.6-1.0 \mathrm{mmol} / \mathrm{l}) .^{1,2,4}$

Drinking water is not the only dietary source of lithium. According to the US Environment Protection Agency, some grains and vegetables are much richer in lithium than drinking water. Moreover, daily lithium intake oscillates between 650 and $3100 \mu \mathrm{g}$ in adults. This means that drinking water can only be a minor contributor to lithium consumption in humans. ${ }^{13}$

\section{Implications}

Further studies are required to relate specific dietary lithium consumption to expected serum lithium levels, as well as to ascertain at what range or threshold, if any, lithium could prevent suicidal behaviour at the population level. Future research may also benefit from accounting for other variables associated with possible variations in suicide rates, for example sociodemographic characteristics or standards of care for people with mental disorders, specifically mood disorders, in each particular geographical area.

Nikolett Kabacs, MD, Cambridgeshire and Peterborough NHS Foundation Trust, Cambridge; Anjum Memon, MBBS, DPhil, Division of Primary Care and Public Health Brighton and Sussex Medical School and NHS Brighton and Hove, Brighton; Thom obinwa, MRCPsych, Cambridgeshire and Peterborough NHS Foundation Trust, Cambridge; Jan Stochl, PhD, Department of Psychiatry, University of Cambridge; Jesus Perez, MD, PhD, Cambridgeshire and Peterborough NHS Foundation Trust and Department of Psychiatry, University of Cambridge, UK

Correspondence: Jesus Perez, Block 7, Ida Darwin, Fulbourn Hospital, Fulbourn, Cambridge, CB21 5EE, UK. Email: jp440@cam.ac.uk

First received 20 Dec 2010, final revision 31 Jan 2011, accepted 23 Feb 2011

\section{References}

1 Cipriani A, Pretty $\mathrm{H}$, Hawton $\mathrm{K}$, Geddes JR. Lithium in the prevention of suicidal behavior and all-cause mortality in patients with mood disorders: a systematic review of randomized trials. Am J Psychiatry 2005; 162: 1805-19.

2 Baldessarini RJ, Tondo L, Davis P, Pompili M, Goodwin FK, Hennen J. Decreased risk of suicides and attempts during long-term lithium treatment: a meta-analytic review. Bipolar Disord 2006; 8: 625-39.

3 Müller-Oerlinghausen B, Felber W, Berghöfer A, Lauterbach E, Ahrens B. The impact of lithium long-term medication on suicidal behavior and mortality of bipolar patients. Arch Suicide Res 2005; 9: 307-19.

4 National Institute for Health and Clinical Excellence. Bipolar Disorder. The Management of Bipolar Disorder in Adults, Children and Adolescents, in Primary and Secondary Care (Clinical Guideline 38). NICE, 2006.

5 Schrauzer GN, Shrestha KP. Lithium in drinking water and the incidences of crimes, suicides and arrests related to drug addictions. Biol Trace Elem Res 1990; 25: 105-13.

6 Ohgami $\mathrm{H}$, Terao $\mathrm{T}$, Shiotsuki I, Ishii $\mathrm{N}$, Iwata $\mathrm{N}$. Lithium levels in drinking water and risk of suicide. Br J Psychiatry 2009; 194: 464-5.

7 Young AH. Invited commentary on . . . Lithium levels in drinking water and risk of suicide. Br J Psychiatry 2009; 194: 466.

8 Desai G, Chaturvedi SK. Lithium in drinking water and food, and risk of suicide. Br J Psychiatry 2009; 195: 271; author reply 271-2.

9 Chandra PS, Babu GN. Lithium in drinking water and food, and risk of suicide. Br J Psychiatry 2009; 195: 271; author reply 271-2.

10 Schrauzer GN, Shrestha KP. Lithium in drinking water. Br J Psychiatry 2010; 196: 159-60; author reply 160.

11 Huthwaite MA, Stanley J. Lithium in drinking water. Br J Psychiatry 2010; 196: 159; author reply 160

12 World Health Organization. The ICD-10 Classification of Mental and Behavioural Disorders: Clinical Descriptions and Diagnostic Guidelines. WHO, 1992.

13 Schrauzer GN. Lithium: occurrence, dietary intakes, nutritional essentiality. J Am Coll Nutr 2002; 21: 14-21. 